\title{
KUALITAS AIR DAN STATUS KESUBURAN PERAIRAN DI TELAGA NGIPIK, WADUK BUNDER DAN TELAGA DOWO DI KABUPATEN GRESIK
}

\author{
Aminin $^{1}$, Gawes Bagus ${ }^{2 *}$, Andrean Fajar Kusuma ${ }^{2}$ \\ ${ }^{1}$ Lecturer in the Aquaculture Study Program, Faculty of Agriculture, University of Muhammadiyah Gresik \\ ${ }^{2}$ Students in the Aquaculture Study Program, Faculty of Agriculture, University of Muhammadiyah Gresik \\ Email : m1n1n.a1924@umg.ac.id; 081249562646
}

\begin{abstract}
Ngipik, bunder and dowo reservoirs or dowo are one of the repositories in Gresik regency located in the center of the city that has been utilized by the community for industrial, agricultural and domestic purposes, while also being used for tourism purposes. The study aims to determine water quality and evaluate the status of water fertility in three reservoirs/lakes (Ngipik, Bunder and Dowo) in Gresik district. The research activities were carried out from 16 to 20 July 2019. The data collection method used a survey method with stratified random sampling at three different stations. The results of water quality measurements show that overall that the water quality in the three reservoirs/ponds is still good for aquaculture activities except Ngipik Lake based on phosphate values of 0.75 - 3 ppm can be categorize including the status of dense eutrophic waters so specific management plans are needed to optimize its utilization. Whereas in the Bunder reservoir and Dowo ponds, the phosphate content has not detected, so its water status is oligotrophic.
\end{abstract}

Keywords: reservoir in gresik, water fertility status, lake ngipik

\begin{abstract}
Abstrak: Waduk atau telaga ngipik, bunder dan dowo merupakan salah satu waduk di kabupaten Gresik yang lokasinya berada di tengah kota yang telah dimanfaatkan masyarakat untuk keperluan industri, pertanian dan domestik, selain itu juga sedikit digunakan untuk keperluan wisata. Penelitian bertujuan untuk mengetahui kualitas air dan mengevaluasi status kesuburan perairan ditiḡa waduk/telaga (Ngipik, Bunder dan Dowo) di kabuapten gresik. Kegiatan penelitian dilaksanakan tanggal 16 sampai 20 Juli 2019. Metode pengumpulan data menggunakan metode survey dengan stratified random sampling pada tiga stasiun yang berbeda. Hasil pengukuran kualitas air menunjukkan bahwa secara keseluruhan bahwa kualitas air $\bar{d}$ i ketiga waduk/telaga masih baik untuk kegiatan budidaya perikanan kecuali telaga Ngipik berdasarkan nilai fosfat sebesar $0,75-3 \mathrm{ppm}$ dapat dikatagorikan termasuk status perairan eutrofik berat sehingga perlu rencana pengelolaan tertentu untuk mengoptimalkan pemanfaatannya. Sedangkan dilokasi waduk Bunder dan telaga Dowo kandungan fosfatnya tidak terdeteksi jadi status perairannya termasuk oligotrofik.
\end{abstract}

Kata kunci: waduk di gresik, status kesuburan perairan, telaga ngipik 


\section{PENDAHULUAN}

\section{Latar Belakang}

Pembangunan sektor industri di Kabupaten Gresik mengalami perkembangan yang signifikan, data statistik daerah menyebutkan selama tahun 2012 terdapat 512 perusahaan baru. Pembangunan sektor industri di Kabupaten Gresik sebagai bagian dari proses pembangunan nasional dalam meningkatkan pertumbuhan ekonomi telah membawa perubahan terhadap kehidupan masyarakat. Perubahan akibat pembangunan industri, selain mendatangkan kesejahteraan bagi masyarakat Gresik juga memberi dampak terhadap sosial ekonomi dan dampak negatif pencemaraan lingkungan yang ada di kota Gresik.

Gresik merupakan salah satu kota industri terbesar di Jawa timur (Pemerintah Kabupaten Gresik, 2012). Perkembangan industrinya sangat berpengaruh terhadap kondisi lingkungan perairan baik sungai, telaga dan laut. Kegiatan pemantauan kondisi perairan umum dapat dilakukan melalui penelitian (evaluasi kelayakan kesuburan perairan) yang dilaksanakan dalam rangka merespon kondisi perubahan lingkungan sekitar, yang trennya kian hari terus mengalami penurunan kualitas air, yang diduga disebabkan oleh masuknya limbah buangan yang dihasilkan dari kegiatan industri, kegiatan pertanian, dan kegiatan domestik (rumah tangga).

Gresik memilki waduk/telaga diwilayah perkotaan diantaranya adalah Waduk/telaga Bunder, Telaga Ngipik dan telaga dowo. Keberadaanya telah dimanfaatkan masyarakat untuk kegiatan pertanian, domestik dan industri. Waduk yang berada di wilayah kota industri, seperti gresik tententunya memilki banyak fungsi diantaranya memberikan dampak positif untuk kesejahteraan masyarakat dalam berbagai kegiatan. Menurut (Widayati, 2007) bahwa manusia menciptakan waduk/telaga dengan ukuran yang kecil atau besar biasanya berfungsi sebagai irigasi pertanian, pengendalian banjir, pembangkit listrik tenaga air, Wisata air (pemancingan), penggelontoran limba industri dan kebutuhan domestik serta keperluan budidaya ikan.

Jadi semakin lama kebutuhan manusia akan pasokan air terus meningkat dari waktu kewaktu, tentunya dalam perkembangannya membutuhkan evaluasi tentang kelayakan kualiatas perairan dari telaga/waduk agar pemanfaatannya sesuai dengan kebutuhan dan bermanfaat untuk berbagai keperluan manusia. Tujuan dari penelitian ini adalah adalah pertama : mengetahui dan mengevaluasi ketiga telaga Ngipik, Bunder dan Dowo termasuk katagori subur, sedang dan tidak subur. Kedua: menentukan layak atau tidak digunakan untuk kegiatan budidaya ikan.

\section{METODE}

\section{Waktu dan tempat}

Penelitian dilaksanakan tanggal 16 sampai 20 Juli 2019. Lokasi penelitian di Telaga Ngipik, Bunder dan Telaga Dowo Kabupaten Gresik. Alat dan bahan yang di gunakan adalah sebagai berikut :

- Perahu

- Pelampung

- Thermometer Hg

- Kotak standar $\mathrm{pH}$
- Amoniak Tes Kit

- Refraktometer

- Secni Disk

- Bola Pimpong 
- DO meter

- Cool box

- Sampel Air/tanah
- Tali Rafia

- Aquades

- Kertas Label

\section{Teknik Pengukuran Parameter}

\section{Suhu}

Suhu air di ukur dengan menggunakan thermometer yaitu dengan cara mencelupkan sampai 3/4 panjang thermometer kedalam air. Diusahakan agar tubuh tidak menyentuh thermometer karena suhu tubuh dapat mempengaruhi suhu pada thermometer. Setelah itu didiamkan beberapa menit sampai dapat dipastikan tanda penunjuk skala berada dalam kondisi tidak bergerak. Kemudian menentukan nilai suhu yang ditunjukkan pada thermometer tersebut dan mencatat hasilnya.

\section{Kekeruhan}

- Botol yang berisi air sampel diaduk dengan cara dibolak-balik agar tidak terjadi endapan.

- Air sampel dipindahkan kedalam tabung reaksi sebanyak 20-30 ml.

- Tabung reaksi dimasukkan kedalam turbidimeter kemudian hasilnya dicatat.

pH air

Perairan dikatakan basah apabila memilki $\mathrm{pH}>7$, sedangkan $<7$ dikatakan $\mathrm{pH}$ asam. Pengukuran $\mathrm{pH}$ suatu perairan dapat menggunakan beberapa cara diantaranya sebagai berikut : Indra perasa, Indikator Tetes, Kertas Lakmus dan pH Meter Digital.

\section{DO (Oksigen Terlarut)}

- Sampel air dimasukkan ke dalam botol oksigen lalu ditutup (jangan ada gelembung) Ditambahkan 0,5 ml MnSO4 dan 0,5 KI, ditutup rapat-rapat dan dibolak-balik +20 kali,setelah itu dibiarkan beberapa menit hingga endapan coklat terbentuk dengan sempurna.

- Ditambahkan $1 \mathrm{ml} \mathrm{H} 2 \mathrm{SO} 4$ pekat kemudian diaduk dengan cara yang sama hingga semua endapan larut (kalau masih ada endapan, ditambahkan lagi $\mathrm{H} 2 \mathrm{SO} 4$ pekat $+0,5 \mathrm{ml}$ ), warna kuning.

- Sampel yang ada dalam botol dituang ke dalam erlemeyer kemudian ditambahkan +5 tetes indikator amilum (warna biru),

- Dititrasi dengan Na2S2O3 0,025 N hingga tidak berwarna dan dicatat ml Na2S2O3 0,025 $\mathrm{N}$ yang digunakan.

\section{Nitrat}

- $2 \mathrm{ml}$ sampel dimasukkan ke dalam tabung reaksi dengan menggunakan pipet, ditambahkan $2 \mathrm{ml} \mathrm{H} 2 \mathrm{SO} 4$ pekat,

- ditambahkan 0,2 ml larutan brucine (4 tetes) kemudian diaduk dan dianginkan,

- diukur pada spektofotometer pada panjang gelombang $420 \mathrm{~nm}$ dan mencatat absorbancenya. 


\section{Fosfat}

- Sampel air dipipet sebanyak $2 \mathrm{ml}$ kemudian dimasukkan ke dalam tabung reaksi,

- ditambahkan $2 \mathrm{ml}$ asam aborat $1 \%$,

- Selanjutnya ditambahkan $3 \mathrm{ml}$ larutan pengoksid,

- Dikocok dan dibiarkan selama 1 jam sehingga terjadi warna biru dan dianalisis pada spektofotometer. Kepekaan warna tergantung pada panjang gelombang $650 \mathrm{~nm}$ (absorbance).

\section{BOD (Biological Oxygen Demand)}

- sampel air sebanyak $50 \mathrm{ml}$ dimasukkan ke dalam Erlenmeyer dengan menggunakan pipet,

- ditambahkan 9,5 ml KMnO4 0,01 N,

- ditambahkan H2SO4 1:410 ml

- Kemdian dipanaskan pada suhu 70-80 oC dan setelah itu didinginkan sampai suhu $20{ }^{\circ} \mathrm{C}$,

- dititrasi dengan $\mathrm{KMnO} 4$ sampai berwarna merah jambu muda/ungu muda, dan mencatat $\mathrm{ml} \mathrm{KMnO} 4$ yang digunakan.

\section{COD (Chemical Oxygen Demand)}

- Erlenmeyer $125 \mathrm{ml}$ dicuci bersih, bebas bahan organic $10 \mathrm{ml}$ air sampel dimasukkan ke dalam Erlenmeyer dengan menggunakan pipet, ditambahkan $5 \mathrm{ml} \mathrm{K2Cr2O}$ dan di aduk

- Kemudian ditambahkan dengan hati-hati $15 \mathrm{ml} \mathrm{H} 2 \mathrm{SO} 4$ pekat (menggunakan ruang asam).

- $\quad$ Erlenmeyer ditutup dengan gelas penutup dan dibiarkan selama selama 30 menit,

- Setelah itu diencerkan dengan menambahkan 7,5 $\mathrm{ml}$ aquades bebas ion dan di aduk

- Ditambahkan 2-3 tetes indicator Ferroin, kemudian dititrasi dengan FAS hingga terjadi

- Perubahan warna dari kuning oranye atau biru kehijauan menjadi merah kecoklatan,

- $\quad$ Setelah itu dibuat larutan blanko dengan $10 \mathrm{ml}$ aquades.

\section{Kecepatan Arus}

Cara Menghitung Kecepatan Arus Air Sungai untuk melakukan teknik penaksiran kecepatan arus air, salah satunya bisa menggunakan metode sebagai berikut:

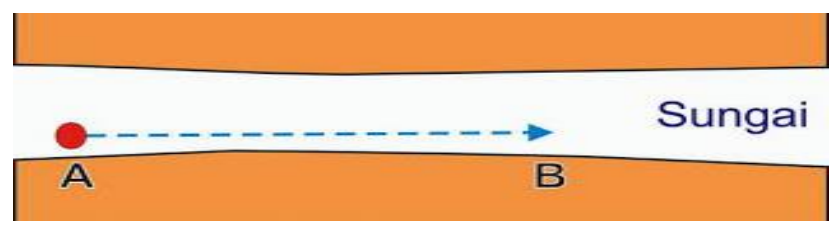

1. Satu orang berdiri di titik A dan satu orang lagi berdiri di titik B (perhatikan gambar di atas). Jarak antara A dan B harus ditentukan terlebih dahulu, semisal 1 meter, 5 meter, atau 10 meter tergantung kecepatan arus air, dimana semakin cepat arus lebih baik semakin jauh.

2. Orang A (orang yang berdiri di titik A) membawa benda yang bisa terapung, sedangkan orang B (orang yang berdiri di titik B) membawa pengukur waktu (stopwatch atau jam).

3. Orang A menjatuhkan benda ke air. Bersamaan dengan itu Orang B menghidupkan penghitung waktu dan mematikannya saat benda tersebut sampai di orang B.

4. Lakukan penghitungan dengan menggunakan rumus sebagai berikut: 


$$
\begin{array}{ll} 
& \text { Di mana: } \\
\mathrm{v}=\text { kecepatan; dengan satuan detik } / \text { meter; menit } / \text { meter; jam } / \mathrm{km} \text { dll } \\
\mathrm{V}=\frac{\mathrm{S}}{\mathrm{t}} \quad \mathrm{l}=\text { jarak; dengan satuan meter, kilometer }(\mathrm{km}) \mathrm{dll}
\end{array}
$$

\section{HASIL DAN PEMBAHASAN}

\section{Keadaan Umum Lokasi Penelitian}

\section{Telaga Ngipik}

Telaga Ngipik atau sekarang biasa disebut dengan Giri Wana Tirta merupakan danau /telaga air tawar buatan yang berasal dari lubang galian bekas eksploitase batu kapur semen Gresik yang memilki luas sekitar $20 \mathrm{Ha}$. (Anonim, 2018). Lokasi telaga berada di area kawasan industri gresik. Sebelah timur berbatasan dengan Stadion Petrokimia Gresik, sebelah selatan berbatasan dengan PT. Kelola Mina Laut, PT. Madsumaya Indoseafood,. Batas sebelah barat yg sering digunakan oleh warga untuk memancing. Hasil pengamatan lapang menunjukkan sebelah timur banyak dipadati oleh tanaman air seperti enceng gondok, dengan jumlahnya yang masih normal. Telaga ini memilki kedalaman yang bervariasi dan tergantung musim. Pada musim penghujan air biasanya penuh sehingga bisa mencapai 3-6 meter. Sedangkan pada musim kemarau tinggal 2-4 meter

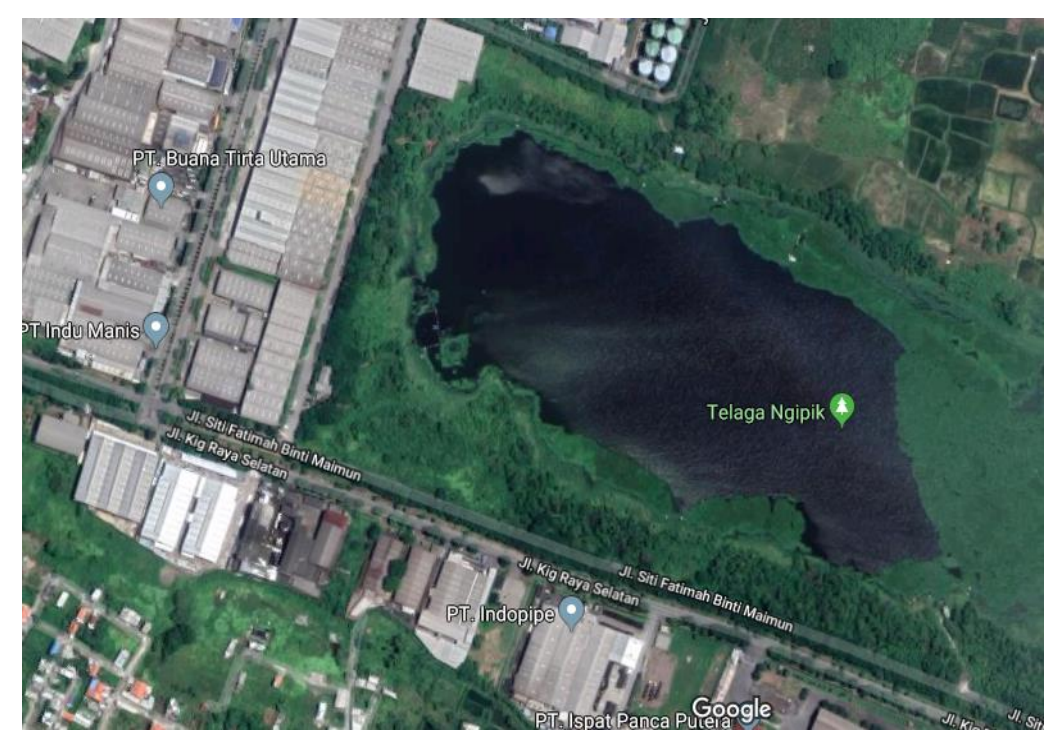

Gambar 1. Telaga Ngipik (Giri Wana Tirta)

\section{Telaga Bunder}

Waduk Bunder termasuk salah satu waduk yang ada di tengah kota Gresik, berlokasi di Beturing, Banjarsari, Cerme, Kabupaten Gresik, Jawa Timur. Air waduk banyak dimanfaatkan masyarakat untuk aktifitas manusia meliputi mandi, memasak, mencuci dan sebagian besar untuk aktifitas pertanian dan sedikit untuk aktifitas perikanan. Pada musim kemarau debet air biasanya sampai habis sehingga dapat terlihat seluruh bagian dasar area waduk. Bisa kitas saksikan kondisi waduk banyak ditumbuhi tanaman liar Bulan Agustus, September dan Oktober waduk biasanya sudah kering tampa air. (Anonim 2009). Waduk 
bunder memiliki luas sekitar 92 hektar dengan daya tampung sebanyak 2,465 juta meter kubik. Namun sekarang hanya terisi seperempatnya saja. sementara itu, luas tanah yang lain menyusut karena terjadi pendangkalan. Jadi untuk memaksimalkan penggunaan waduk tersebut perlu dilakukan upaya pendalaman dengan cara pengerukan menggunakan alat-alat berat sehingga mampu menyediakan kebutuhan air sampai akhir musim kemarau.

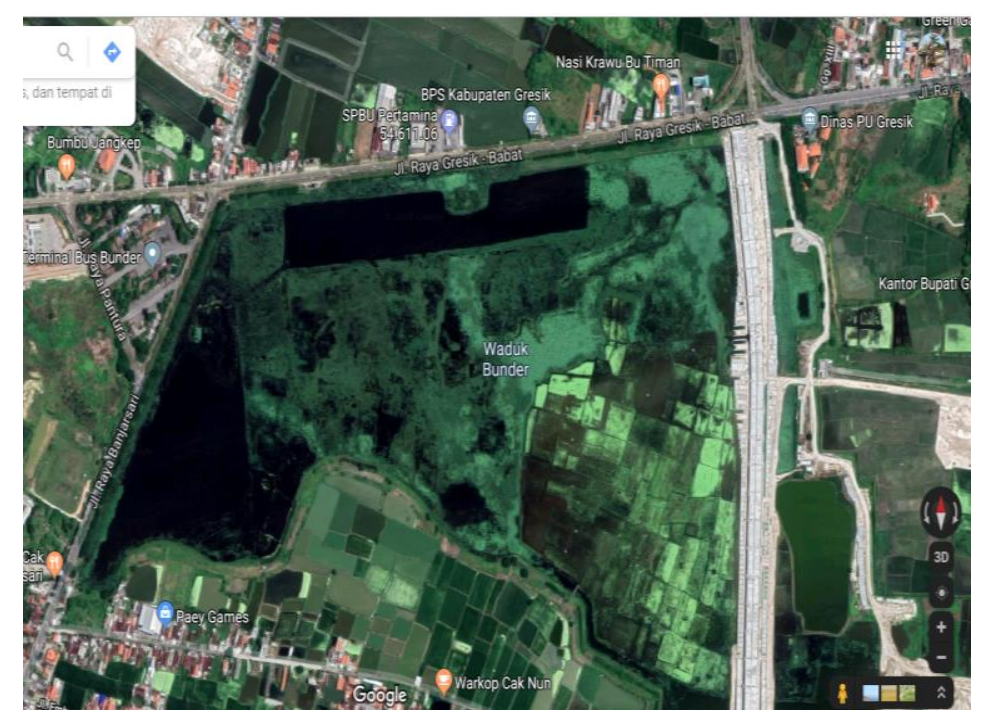

Gambar 2. Waduk Bunder

\section{Hasil Pengukuran Parameter Kualitas Air Dan Evaluasi Kelayakan Kesuburan Perairan Di 3 Waduk/Telaga Di Kota Gresik}

Kegiatan Pengambilan data kualitas fisika dan kimia dilakukan selama penelitian untuk menunjukkan kondisi air relatif terhadap kebutuhan biota air bahkan menjadi ukuran standart terhadap kesehatan ekosistem air. Hasil pengukuran digunakan untuk menilai status kesuburan perairan. Pengambilan sampel meliputi suhu, $\mathrm{pH}$ dan $\mathrm{DO}$, kecerahan, $\mathrm{pH}$ tanah, Nitrat, fosfat dan lain-lain. Nilai rata - rata hasil pengukuran kualitas air 3 telaga/waduk disajikan pada tebel 1 .

Tabel 1. Hasil Pengukuran rata- rata kualitas 3 waduk/telaga di kota Gresik

\begin{tabular}{|l|l|l|l|l|}
\hline \multirow{2}{*}{ Parameter Kualiatas Air } & \multicolumn{3}{|c|}{ Nama Telaga } & Nilai \\
\cline { 2 - 4 } & Ngipik & Bunder & Dowo & Optimal \\
\hline Suhu $\left({ }^{\circ} \mathrm{C}\right)$ & 29,6 & 28,3 & 30,63 & \\
\hline $\mathrm{pH}$ & 9,6 & 8,39 & 10,6 & \\
\hline DO (ppm) & 4 & 5 & 6 & \\
\hline Warna Air & $\begin{array}{l}\text { Berwarna } \\
\text { hijau }\end{array}$ & $\begin{array}{l}\text { Hijau } \\
\text { kecoklatan }\end{array}$ & Coklat jernih & \\
\hline Kecerahan $(\mathrm{cm})$ & 30 & $35 \mathrm{~cm}$ & 50 & \\
\hline Salinitas $(\mathrm{ppt})$ & 0,23 & 0,12 & 0,16 & \\
\hline $\begin{array}{l}\text { Kecepatan } \\
(\mathrm{m} / \text { menit })\end{array}$ & 0,083 & 0,011 & 0,008 & \\
\hline
\end{tabular}




\begin{tabular}{|l|l|l|l|c|}
\hline Kedalaman $(\mathrm{m})$ & 6 & 3 & 2 & \\
\hline Kadar Nitrat $(\mathrm{ppm})$ & 0,5 & Tidak terdeteksi & Tidak terdeteksi & $3-5$ \\
\hline Fosfat $(\mathrm{ppm})$ & $0,75-3$ & Tidak terdeteksi & Tidak terdeteksi & $0,1-0,25$ \\
\hline pH tanah & 7 & 6,5 & 7 & $6-9$ \\
\hline Potensial Redoxs $(\mathrm{mV})$ & -106 & -132 & -163 & $0,11-0,05$ \\
\hline
\end{tabular}

\section{Suhu}

Hasil suhu rata - rata tiap telaga/waduk berkisar antara 28,3-30,63 ${ }^{0} \mathrm{C}$. Hasil ini menunjukkan bahwa perairan tersebut masih sesuai dengan kisaran toleransi untuk kehidupan ikan. Suhu adalah parameter ukur kualitas air faktor fisika yang sangat penting bagi organisme hidup diperairan, kemampuan dalam melarutkan gas-gas yang diperlukan untuk fotosintesis seperti $\mathrm{CO} 2$ dan $\mathrm{O} 2$, gas-gas tersebut mudah terlarut pada suhu rendah dari pada suhu tinggi dikarenakan kecepatan fotosintesis ditingkatkan oleh suhu rendah. Fluktuasi suhu pada perairan danau/waduk pada malan dan siang hari relatif stabil, karena perbedaan suhu di daerah tropis hanya $10{ }^{\circ} \mathrm{C}$. Namu dalam kondisi tertentu atau adanya blooming plankton bisa berbahaya terhadap kehidupan biota perairan hal ini dapat dipengaruhi oleh pengadukan, kedalaman dan besar kecilnya intensitas matahari pada perairan (KKP, 2016)

\section{Oksigen terlarut (DO)}

Hasil pengukuran oksigen terlarut (DO) tertinggi dari 3 waduk/telaga adalah telaga dowo sebesar $6 \mathrm{mg} / \mathrm{L}$ kemudian disusul telaga bunder dan terendah telaga ngipik sebesar 4 $\mathrm{mg} / \mathrm{L}$ ). Waduk dowo merupakan telaga air tawar hasil lubang galian eksploitasi batu kapur Pt. Semen gresik, telaga ini jarang dimanfaatkan oleh masyarakat untuk berbagai kegiatan manusi seperti mandi, memasak dan air minum bahkan kegiatan pertanian sehingga jumlah debet airnya melimpah. Waduk tersebut airnya jernih dengan tingkat kecerahan sampai 50 $\mathrm{cm}$. Tidak banyak tanaman liar diarea telaga hanya sedikit ganggang air tawar di tengah dan dasar perairan. Tanaman air ditelaga dowo tidak mudah tumbuh karena kandungan fosfat, nitrat tidak terdeteksi.

\section{Kadar Nitrat}

Nitrat merupakan salah satu unsur makro dalam suatu perairan karena keberadaanya menjadi faktor pembatas terhadap pertumbuhan biota air seperti alga karena sangat di butuhkan nitrogen dalam proses fotosintesis. Agar tumbuh dengan optimal biasanya membutuhkan kisaran nitrat sebesar 0,9-3,50 ppm (Andarias, 1992). Berbeda dengan pernyataan Tambaru dan Samawi (1996) bahwa kebutuhan nitrat oleh setiap alga sangat beragam, dengan kadar nitrat dibawah 0,1 atau diatas $45 \mathrm{mg} / \mathrm{l}$, maka nitrat merupakan faktor pembatas, jadi pada kadar tersebut nitrat bersifat toksik. Hasil Pengukuran dari 3 telaga yang ada menunjukkan terdapat 2 telaga/waduk (waduk bunder dan dowo) kadar nitrat tidak terdeteksi sedangkan telaga Ngipik terdeteksi dengan nilai yang tinggi sebesar 0,5 ppm. Menurut Effendi (2003) kandungan nitrat disuatu perairan apabila lebih dari 0,2 dapat mengakibatkan eutrofikasi. Biasanya ini ditandai dengan munculnya tanaman air/enceng gondok, kelekap serta fitoplankton dari jenis alga hijau diperairan. 


\section{Fosfat}

Berdasarkan tabel (1)Terukur kadar fosfat pada waduk ngipik sebesar 0,75 - 3 ppm sedangkan telaga dowo dan waduk bunder tidak terdeteksi. Kadar fosfat waduk Ngipik tergolong perairan yang memilki kesuburan tinggi. Pada kondisi tersebut perairan akan mudah tumbuh jenis alga, tanaman air seperti enceng gondok dan lain-lain. Tingkat kesuburan ini disebabkan oleh tingginya nilai fosfat di dalam waduk. KKP (2016) mengatakan, nilai fosfat dalam budidaya ikan yang baik adalah minimal 0,1-5 mg/l. Namun untuk tambak super intensif, nilai fosfat yang dipersyaratkan minimal 0,01.

Konsentrasi fosfat yang cukup tinggi dapat dikategorikan perairan dengan tingkat kesuburan tinggi. Kesuburan yang tinggi menyebabkan eutrofikasi yang berakibat kurang baik bagi perairan karena terlalu banyak fitoplankton sehingga mengurangi nilai oksigen terlarut dan $\mathrm{pH}$ perairan. Kesuburan perairan yang tinggi dapat dikurangi dengan melakukan pergantian air untuk mendapatkan nilai fosfat yang optimal (Dede et al., 2014).

Nilai kesuburan perairan dapat ditentukan oleh kadar ortofosfat diperairan. Dalam hal ini kesuburan berdasarkan kadar ortofosfat diklasifikasikan menjadi tiga, Pertama : perairan oligotrofik (tidak subur) yang memliki kadar/jumlah ortofosfat 0,003-0,01 mg/1, Kedua : perairan mesotrofik (sedang) memiliki kadar/jumlah ortofosfat 0,011-0,03 mg/l. Ketiga : perairan eutrofik (sangat subur) memiliki kadar ortofosfat 0,031-0,1 mg/l (Iksan 2005). Senyawa fosfat dalam perairan berasal dari sumber alami seperti erosi tanah, buangan hewan dan lapukan tumbuhan serta dari laut itu sendiri. Sebagian besar ketersediaan fosfor diperairan berasal dari pelapukan batuan mineral yang hanyut diperairan kemudian fosfat diabsorbsi oleh fitoplankton dan seterusnya masuk ke dalam rantai makanan. Dalam air laut, kadar rata-rata fosfat adalah sekitar $2 \mathrm{ug}$ at PO4-p/l.

\section{pH Tanah}

pH tanah merupakan derajat kemasaman atau kebasaan dari tanah suatu perairan yang digunakan untuk kegiatan budidaya, tingkat kemasaman dan kebasaan ditandai dengan konsentrasi ion hidrogen $\left(\mathrm{H}_{+}\right)$. Hasil pengukuran menunjukkan $\mathrm{pH}$ tanah untuk waduk bunder sebesar 6,5 dengan nilai $\mathrm{pH}$ tertinggi di bandingkan dengan nilai $\mathrm{pH}$ waduk telaga dowo (7) dan telaga ngipik (7). Konsentrasi ion hidrogen yang bersifat masam menunjukan nilai $\mathrm{pH}$ dibawah 7, sedangkan ion hidrogen yang bersifat basa memiliki nilai $\mathrm{pH}$ diatas 7 . Nilai 7 menunjukan nilai $\mathrm{pH}$ dalam keadaan normal. Nilai $\mathrm{pH}$ tanah tambak harus bersifat netral atau sedikit lebih tinggi dan tidak berpotensi bersifat masam (Suhaimi et al., 2013). pH tanah untuk waduk bunder lebih tinggi di duga berasal dari sisa-sisa hasil pemupukan dari aktifitas pertanian ketika musim kemarau. Menurut Poernomo (1992) pH tanah dari 3 waduk/telaga kategori baik/subur dan termasuk memilki kelayakan tinggi untuk aktifitas budidaya ikan.

\section{Potensial Redoxs}

Nilai potensial redoks dari ketiga waduk/telaga terukur rata-rata Ngipik $(-106 \mathrm{mV})$, Bunder $(-132 \mathrm{mV})$ dan dowo $(-163 \mathrm{mV})$. Menurut (Utojo et al., 2008) bahwa Nilai potensial reduksi dan oksidasi tanah tambak berkisar (-217)-(+114) $\mathrm{mV}$ dan (-282)-(+160) mV. Kisaran nilai tersebut masih dalam kategori baik untuk kegiatan budidaya ikan, terutama dalam pertukaran ion dan peran bakteri sebagai mediator Nilai. Potensial redoks merupakan potensi oksidasi dan reduksi pada tanah. Tanah dengan nilai redoks positif menunjukan kondisi 
anoksidasi dan terjadi proses transformasi biokimia. Nilai redoks dengan angka minus yang tinggi menunjukan bahwa tanah sangat membutuhkan oksigen di dalam melakukan perombakan bahan organik senyawa komplek menjadi senyawa sederhana (Supratno, 2006). Nilai minus menunjukan tanah dalam kondisi tereduksi, hal ini disebabkan oleh tanah yang sudah lama tergenang sehingga membentuk kondisi reduksi (Rachmansyah dan Mustafa, 2011).

\section{KESIMPULAN DAN REKOMENDASI}

Secara umum kualitas air di tiga telaga/Waduk berdasarkan aspek fisika, kimia, dan biologi, merupakan perairan yang masih baik dan mendukung kehidupan organisme air. Status kesuburan perairan Telaga Ngipik berdasarkan nilai fosfat sebesar 0,75-3 ppm dapat dikatagorikan termasuk status perairan eutrofik berat sehingga perlu rencana pengelolaan tertentu untuk mengoptimalkan pemanfaatannya. Sedangkan waduk Bunder dan telaga Dowo kandungan fosfatnya tidak terdeteksi jadi status perairannya termasuk oligotrofik.

\section{UCAPAN TERIMA KASIH}

Terima kasih diucapkan kepada Gawes Bagus, Andrean Fajar Kusuma dan tim evaluasi perairan Himpunan Mahasiswa Akuakultur UMG atas bantuannya dalam pengambilan sampel di lapangan.

\section{DAFTAR PUSTAKA}

Anonim 2018, Telaga Ngipik, Wisata Meriah dan Tempat Mancing Asik di Kota Gresik.. Https://www.kompasiana.com. Di akses 14 Nopember 2019 pukul 12:42 WIB.

Anonim 2009, "Telaga dan Waduk di Gresik Menyusut", https://regional.kompas.com. di akses 22 Agustus 2019 pukul 13.30 WIB.

Darmono. 2001. Lingkungan Hidup dan Pencemaran : Hubungan dengan Toksiologi Senyawa Logam. UI Press, Jakarta.

Dede, H., R. Aryawati dan G. Diansyah. 2014. Evaluasi Tingkat Kesesuaian Kualitas Air Tambak Udang Berdasarkan Produktivitas Primer PT. Tirta Bumi Nirbaya Teluk Hurun Lampung Selatan. Maspari Journal Vol. 6 (1), hal. 32-388

Effendi, H. 2003. Telaah kualitas air bagi pengelolaan sumber daya dan lingkungan perairan. Kanisius (Anggota IKAPI). Yogyakarta, $258 \mathrm{hlm}$.

Utojo dan A.M. Tangko. 2008. Status, Masalah, dan Alternatif Pemecahan Masalah pada Pengembangan Budidaya Udang Vannamei (Litopenaeus Vannamei) di Sulawesi Selatan. Media Akuakultur Volume 3 Nomor 2.

Permen KKP. 2016. Peraturam Menteri Kelautan dan Perikanan No. 7 tahun 2016 Tentang Pedoman Umum Pembesaran Udang Windu (Panaeus monodon) dan Udang Vaname (Litopenaeus vannamei). Kementerian Kelautan dan Perikanan

Poernomo, A. 1992. Pemilihan lokasi tambak udang berwawasan lingkungan, CRIFI Pub., 40 hlm

Rachmansyah dam Mustafa, 2011. Evaluasi Kesesuaian Lahan Aktual Tambak Yang Ada di Kabupaten Tanjung Barat Provinsi Jambi. J. Ris. Akuakultur Vol. 6 No. 2 Hal. 311324

Supratno, T, KP. 2006. Evaluasi Lahan Tambak Pesisir Jepara Untuk Pemanfaatan Budidaya 
Ikan Kerapu. TESIS. Universitas Diponegoro. Semarang

Suhaimi, R. A., Hasnawi., dan E. Ratnawati. 2013. Kesesuaian Lahan Untuk Budidaya Udang Windu (Paneus monodon) di Tambak Kabupaten Brebes, Jawa Tengah. J. Ris Akuakultur Vol. 8 No. 3, Hal. 465-477.

Widiyati, A, 2007. Dampak Pembangunan Waduk Terhadap Kelestarian Biodiversity. Balai Riset Perikanan Air Tawar. Bogor 